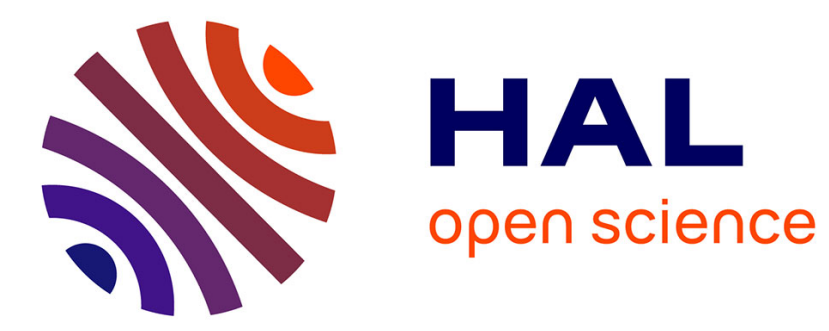

\title{
Net pay determination by Dempster rule of combination: Case study on Iranian offshore oil fields
}

Pedram Masoudi, Bita Arbab, Hossein Mohammad Rezaei

\section{To cite this version:}

Pedram Masoudi, Bita Arbab, Hossein Mohammad Rezaei. Net pay determination by Dempster rule of combination: Case study on Iranian offshore oil fields. Journal of Petroleum Science and Engineering, 2014, 123, pp.78 - 83. 10.1016/j.petrol.2014.07.014 . insu-01382425

HAL Id: insu-01382425

https://hal-insu.archives-ouvertes.fr/insu-01382425

Submitted on 17 Oct 2016

HAL is a multi-disciplinary open access archive for the deposit and dissemination of scientific research documents, whether they are published or not. The documents may come from teaching and research institutions in France or abroad, or from public or private research centers.
L'archive ouverte pluridisciplinaire HAL, est destinée au dépôt et à la diffusion de documents scientifiques de niveau recherche, publiés ou non, émanant des établissements d'enseignement et de recherche français ou étrangers, des laboratoires publics ou privés. 


\section{Net Pay Determination by Dempster Rule of Combination,}

\section{Case Study on Iranian Offshore Oil Fields}

Pedram Masoudi (Corresponding author); Researcher of Petroleum Geoscience, Department of Research and Technology, Iranian Offshore Oil Company; Presently, PhD Student at University of Tehran;+98-912-4020733; masoudip@ut.ac.ir

BitaArbab; Senior Petrophysicist, Department of Petrophysics, Iranian Offshore Oil Company

Hossein Mohammad Rezaei; Head of Department of Petrophysicist, Iranian Offshore Oil Company

\section{Abstract}

Net pay detection is a key stage in reservoir characterization for several purposes: reserve estimation, reservoir modeling and simulation, production planning, etc. Determining productive zones always is simultaneous with some amount of uncertainty due to lack of enough data, insufficiency of knowledge and wild-nature of petroleum reservoirs. It becomes even more challenging in carbonates, because of their highly heterogeneous environment. Conventionally, evaluating net pays is done by applying petrophysical cut-offs on well-logs, which results in crisp classification of pay or non-pay zones. In addition, cut-off-based method is developed in sandstones, and does not provide suitable results in carbonates at all. Proposed methodology of this work, Dempster-Shafer Theory, is a generalization of Bayesian Theory of conditional probabilities. Net pays are studied in two oil reservoirs by this theory; one of them is carbonate reservoir of Mishrif, the other is sandy Burgan reservoir. For validation, results 
are compared to well tests and output of conventional cut-off method. The advantages of using Dempster-Shafer Theory, comparing to conventional cut-off-based method in studying net pays is: to have a continuous fuzzy output, based on geological facts, with high generalization ability and more compatibility with well test data.

Keywords: production rate, net pay, uncertainty, well test, Dempster-Shafer Theory

\section{Introduction}

We drill to produce; therefore, finding productive zones (net pays) backs to the very first drilled wells in the story of oil industry. The history of net pay determination could be categorized into three parts. In the first part, specialists used to determine net pays while drilling. Second part starts just after invention of logging tools. In this part, finding productive zones is based on indirect methods; i.e. petrophysicists used to "infer" where the oil is accumulated with appropriate reservoir pressure. Third part is followed by development of computer and computing systems in net pay determination. In this part, there is not a significant hardware progress but software are highly improved, based on acquired data, mostly logs. The methodologies vary from simple statistical assessments to complex data-driven methodologies. The below chart is summary of utilized tools or methods for net pay determination:

Table 1 List of articles, and introduced methodologies, datasets, instruments for net pay determination.

\begin{tabular}{|c|c|c|c|}
\hline Part & Article(s) & Methodology/ Datasets/Instrument & Descriptions \\
\hline \multirow{4}{*}{ 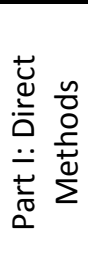 } & (Millikan, 1925) & Gas-meter & \\
\hline & (Connell et al., 1986) & Flourimetric & \\
\hline & $\begin{array}{l}\text { (Chaudhry, 2004; Matthews } \\
\text { and Russell, 1967) }\end{array}$ & $\begin{array}{l}\text { Drill Stem Test (DST) and other well } \\
\text { testing methods }\end{array}$ & \\
\hline & (Cooke-Yarborqugh, 1984) & Cased-hole Wireline Formation Tester & New tool for well testing \\
\hline \multirow{3}{*}{ 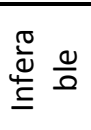 } & (Snyder, 1971) & Gamma and resistivity logs & \\
\hline & (Flower, 1983) & Resistivity and shear sonic logs & \\
\hline & (Cooke-Yarborqugh, 1984) & Pressure meter & New instrument as a quick- \\
\hline
\end{tabular}




\begin{tabular}{|c|c|c|c|}
\hline & & & look \\
\hline & (Deakin and Manan, 1998) & $\begin{array}{l}\text { Conventional logs, capillary pressure of } \\
\text { cores and interpreted image logs }\end{array}$ & Gas reservoirs \\
\hline & (Worthington, 2000) & Gamma, caliper and self-potential logs & $\begin{array}{l}\text { recognizing low-resistivity } \\
\text { pays, tight sands }\end{array}$ \\
\hline & (Nottale, 1996) & Conventional logs and core data & $\begin{array}{l}\text { Application of rock typing in } \\
\text { net pay detection }\end{array}$ \\
\hline \multirow{9}{*}{ 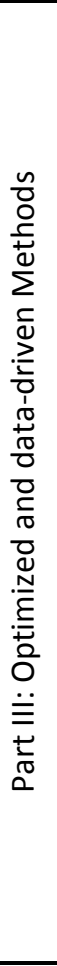 } & $\begin{array}{l}\text { (Worthington and Cosentino, } \\
\text { 2005) }\end{array}$ & $\begin{array}{l}\text { Shale volume, porosity and water } \\
\text { saturation }\end{array}$ & $\begin{array}{l}\text { Review paper on cut-off } \\
\text { method }\end{array}$ \\
\hline & (Jensen and Menke, 2006) & Cut-off estimation & $\begin{array}{l}\text { Statistical issue for estimating } \\
\text { cut-off }\end{array}$ \\
\hline & (Worthington, 2008) & Dynamic cut-off & \\
\hline & (Worthington, 2010) & $\begin{array}{l}\text { Cut-off/ Shale volume, porosity and } \\
\text { water saturation }\end{array}$ & Review paper on net pay \\
\hline & (Mahbaz et al., 2011) & $\begin{array}{l}\text { Optimization of cut-offs based on } \\
\text { statistics, viscosity }\end{array}$ & $\begin{array}{l}\text { Case study of Burgan } \\
\text { reservoir in offshore }\end{array}$ \\
\hline & (Masoudi et al., 2011) & $\begin{array}{l}\text { Diffusivity equation/ Viscosity, } \\
\text { compressibility, porosity and } \\
\text { permeability from cores, conventional } \\
\text { logs }\end{array}$ & $\begin{array}{l}\text { Case study of Sarvak } \\
\text { Formation, a carbonate } \\
\text { reservoir }\end{array}$ \\
\hline & (Masoudi et al., 2012a) & $\begin{array}{l}\text { Bayesian classifier/ Shale volume, } \\
\text { porosity, water saturation and well test }\end{array}$ & $\begin{array}{l}\text { Case study of Sarvak } \\
\text { Formation, a carbonate } \\
\text { reservoir }\end{array}$ \\
\hline & (Masoudi et al., 2012c) & Fuzzy fusion/ LLD, LLD:LLS and well test & $\begin{array}{l}\text { Case study of Sarvak } \\
\text { Formation, a carbonate } \\
\text { reservoir }\end{array}$ \\
\hline & (Masoudi et al., 2012b) & $\begin{array}{l}\text { Comparing methods of cut-off, } \\
\text { diffusivity, Bayesian and Fuzzy }\end{array}$ & $\begin{array}{l}\text { Case study of Sarvak } \\
\text { Formation, a carbonate } \\
\text { reservoir }\end{array}$ \\
\hline
\end{tabular}

The majority of above mentioned articles are mainly based on cut-off method to determine net pays. There are only some novel methodologies in part III, which the bases are on data fusion approaches: Bayesian and fuzzy theories. The biggest pitfall of well-known cut-off procedure is that this method categorizes the whole gross into pay and non-pay zones that do not provide a realistic view of non-crisp nature of drilled well. Due to success of data fusion-based methods in assessing productive zones fuzzily in carbonates; in this study, another fusion-based approach, based on Dempster-Shafer Theory (DST), is developed in order to evaluate productive zones by belief function.

\section{Why to Solve a Single Problem by Multiple Solutions?}


Due to the literature, corresponding author have already proposed other solutions to the problem of "Net Pay Determination" based on different theories: Bayesian, fuzzy and diffusivity equation. There is a true critic: "Is it necessary to propose new methodology to solve a problem, which has already been solved by previous solutions?" In another word, wouldn't be redundant, approaching a single problem by multiple solution?

Authors believe that the answer depends on the standpoint of which we are looking from. In general for petroleum industry, there are two viewpoints: "Engineering" and "Science". It is ideal for engineers to design the easiest and fastest pathway towards destination, meanwhile meeting required criteria, accuracy and precision. On the other hand, for scientists, it is essential to explore all possible ways, categorizing methodologies and achievements with less economic considerations, in order to benefit of findings, as is required by engineers. Hence, science is a support for engineering. In another word, science is a domain for engineering, and the more progressed the science is, the wider domain for engineers to act and build within. Therefore having multiple solutions for a single problem is power, and improves engineer's abilities, and confidence of their designing and decisions.

Specifically about the case of "Net Pay Detection", we should consider highly heterogeneous condition of reservoirs. Reservoir conditions vary a lot. This heterogeneity results in uncertainty of geoinformation and interpretations, subsequently a big lack of knowledge in new areas. Even the same formation might show varying behavior in different locations or conditions! Therefore, in fact, "Net Pay Detection" is a general concept, containing several sub-problems: "Net Pay Detection: in Carbonates/ in Clastic reservoirs/ by using NMR log/ by Benefiting of Well Test Results/ ... ".

(Worthington and Cosentino, 2005) has listed 31 works on net pay determination, introducing studied reservoir rocks and contained fluid briefly. Set of reservoir rocks consists of ten types: sandstone, shaly sand, laminated shaly sands, laminated sandstone, silty sandstone, laminated muds 
and sands, tight sandstone, carbonate, limestone and dolomite. Set of fluid contents contains six types: oil, oil and gas, gas, gas condensate, heavy oil and extra-heavy oil. Surely, number of all possible conditions exceeds multiplication of ten by six, i.e. 60 situations! This number shows a big diversity in the problem of "net pay".

In this situation, some methodologies might not be applicable in some conditions, e.g. some methodologies are designed for simpler sandy reservoirs, and not applicable in wild-nature carbonate reservoirs or vertically heterogeneous environment of laminated reservoirs. Hence, having multiple approaches makes industry capable to handle various conditions. In this work, two reservoir conditions are considered in order to check proposed DST methodology in two prominent reservoir environments: carbonate and clastic.

\section{Datasets and Geologic Settings}

Developed methodology is applied in two reservoirs: a carbonate and a sandy reservoir of two different oil fields. Both structures are of Iranian offshore oil fields in the Persian Gulf, and geological aspects of studied reservoirs are described as follow. Utilized data in both datasets consists of calculated porosity, shale content and water saturation, in addition to well test results for verification.

An important oil reservoir in the Persian Gulf and the Middle East, called Mishrif formation, equivalent to Upper Sarvak Formation with the age of Cenomanian- Early Turonian was available for this work. Based on sedimentologic studies, it is understood that Mishrif is deposited in a regressive cycle: starts with basinal (outer self) environment, followed by slope environment, continues with shoal or reefal environment and ends with lagoonal environment(Al-Dabbas et al., 2010).In the studied oil field (name is not enclosed due to confidentiality, instead we call it Field " $\mathrm{C}$ " due to studying a carbonate 
reservoir through) Mishrif formation is overlaid on Khatiyah formation, and is distinguishable from overlaying Formation of Laffan by famous and distinct unconformity of Upper Cretaceous. The available dataset contains seven oil wells, drilled on " $C$ " field, which is a relatively small oil field in the Persian Gulf; close to the border of Iran and Qatar. Zone of Oil-Water Contact (OWC) has been detected clearly in all the seven wells within Mishrif reservoir.

Sandy Burgan reservoir, Middle Cretaceous (Albian era), is a Member of Kazhdumi Formation (Bashari, 2007; Mahbaz et al., 2011). As it is reported from the studied field (we render this field as "S" field due to studying a sandy reservoir through), Burgan Member is overlaid on unnamed clastics, after a sedimentation gap. Sequence stratigraphy of Burgan Member in an adjacent offshore oil field, Forouzan; shows that Burgan consists of four sedimentation sequences that each one starts from shallow sandy facies, and ends with deeper shaly facies(Honarmand and Moallemi, 2009). The available dataset in this oil field is comprised of five drilled wells.

\section{Methodologies}

Net pay determination is done by two methodologies: conventional and proposed. The conventional method is cut-off-based method, which provides a crisp output. The results of cut-off method are considered as a bench mark for assessing proposed method. The developed method is based on Dempster-Shafer Theory (DST). The methodologies are introduced as follow.

\section{Conventional Cut-off-based Methodology}

Conventional cut-off-based methods provides a crisp (0/1) output (Masoudi et al., 2012a; Masoudi et al., 2012b; Masoudi et al., 2012c; Masoudi et al., 2011; Worthington, 2010).Due to reports 
of Iranian Offshore Oil Company (IOOC), kaolinite is dominant shale mineral in Mishrif reservoir of " $\mathrm{C}$ " oil field; furthermore, kaolinite-porosity plot is produced in each well, in order to distinguish different reservoir facies. Then, borders of each reservoir facies is interpreted as cut-off value of porosity or kaolinite. Cut-off of water saturation is inferred from histograms of water saturation in each well, where two distributions are distinguishable. Figure 1 shows procedure of net pay determination by cut-off method.

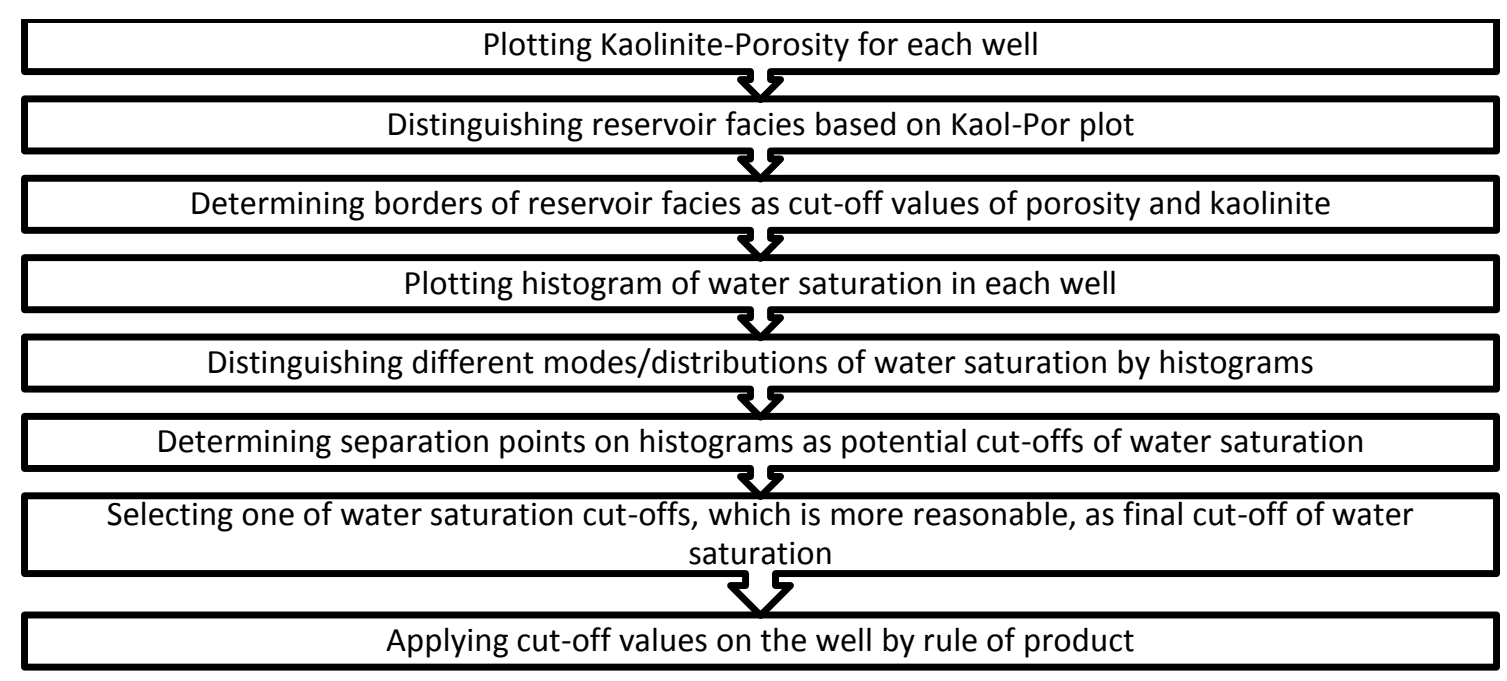

Figure 1Procedure of net pay determination by cut-off methodology.

\section{Dempster-Shafer Theory (DST)}

"Dempster-Shafer Theory of Evidences" (Dempster, 1967), "Bayesian Theory of Conditional Probability" and "Possibility Theory" (Negoita et al., 1978) are three major schools of thought in assessing Body of Evidences and reasoning. Dempster-Shafer Theory (DST) is generalization of Bayesian Theory, developed under the concept of "Subjective Probability" (Shafer, 1990). Reputation of DST is in decision-making in uncertain situations (Rakowsky, 2007); like here in uncertain condition of petroleum 
reservoirs. In fact, DST is another mathematical approach for assessing uncertainty (Sentz and Ferson, 2002).

Aminzadeh is the first researcher who has used DST in uncertainty assessment in petroleum exploration. It is reported in his research that by fusing opinions of two specialists about probability of oil accumulation in a reservoir, uncertainty is lowered significantly. In his sample, the first expert has claimed that the chance of oil accumulation in a prospect is at least $40 \%$ (i.e. $60 \%$ ignorance). The second expert has claimed that the probability of existence of water or oil is at least $60 \%$ (i.e. $40 \%$ ignorance). By using DST to combine these two opinions, it is inferred that chance of finding "oil" is between $40 \%$ and $64 \%$ (i.e. $64 \%-40 \%=24 \%$ ignorance); and chance of finding "water or oil" is from $36 \%$ to $60 \%$ (i.e. $60 \%-36 \%=24 \%$ ignorance). Therefore the ignorance range is lowered from $60 \%$ or $40 \%$ to $24 \%$.

As in the above sample, output of DST is a range of probability, and boundaries are called "Plausibility" and "Belief", and could be calculated by "Plausibility Function" and "Belief Function" respectively. There are some formula for calculating Belief and Plausibility but the easiest way is by using another function called "Mass Function", which should satisfy the below conditions:

$$
\begin{gathered}
m(\varnothing)=0 \\
\sum_{i=1}^{2^{n}} m\left(A_{i}\right)=1
\end{gathered}
$$

Where, " $m$ " is Mass Function; " $A_{i}$ " is a possible state out of totally " ${ }^{n "}$ states; while " $n$ " is number of elements/ variables in the system under investigation. Based on Mass Function, Belief and Plausibility Functions are defined as: 


$$
\begin{aligned}
& \operatorname{bel}\left(A_{i}\right)=\sum_{B_{j} \subseteq A_{i}} m\left(B_{j}\right) \\
& \operatorname{pl}\left(A_{i}\right)=\sum_{A_{i} \cap B_{j} \neq 0} m\left(B_{j}\right)
\end{aligned}
$$

In fact, Belief Function is a pessimistic viewpoint about occurrence of " $A_{i}$ "; whereas, Plausibility Function is an optimistic standpoint. In mathematical language, the relationship between these functions and probability is:

$$
m\left(A_{i}\right) \leq \operatorname{bel}\left(A_{i}\right) \leq p\left(A_{i}\right) \leq p l\left(A_{i}\right)
$$

In the case of a multisensory system, Mass Function could be calculated for the whole system by using Dempster Rule of Combination. This rule (equations 8 and 9 are Dempster Rule of Combination for a two-sensory system) uses Mass Functions of sensors $\left(m_{1}\right.$ and $\left.m_{2}\right)$ in order to produce a new Mass Function for decision-making about whole the system; in another word, for sensor fusion (Liu and Yager, 2008; Rakowsky, 2007). It is essential to mention that Dempster Rule of Combination is a purely conjunctive (AND) operation; and mathematically, it is recommended to combine independent bodies of evidences, $\left(m_{1}\right.$ and $m_{2}$ ) (Sentz and Ferson, 2002); however this constraint is not a big restriction for engineering use if output satisfies requirements.

$$
\begin{gathered}
m(A)=\frac{\sum\left\{m_{1}(B) m_{2}(C) \mid B \cap C=A\right\}}{\sum\left\{m_{1}(B) m_{2}(C) \mid B \cap C \neq \varnothing\right\}} \\
m(A)=\frac{\sum\left\{m_{1}(B) m_{2}(C) \mid B \cap C=A\right\}}{1-\sum\left\{m_{1}(B) m_{2}(C) \mid B \cap C=\emptyset\right\}}
\end{gathered}
$$

\section{Proposed DST-based Methodology}


For proposed method, the same inputs of conventional cut-off method, i.e. porosity, shale content and water saturation are used to determine net pay zones. The authors selected the same input set forboth conventional and proposed methods just to examine functionality of the proposed method versus conventional method apart from the effect of input selection. Then, for each input parameter, the simplest Mass Function is created in a way that higher value shows good reservoir quality:

$$
\begin{gathered}
m(\text { porosity })=\text { porosity } \\
m(\text { shale })=1-\text { shale } \\
m(\text { water saturation })=1-\text { water saturation }
\end{gathered}
$$

Thereafter, Dempster Rule of Combination (equation 8 or 9) is used in order to fuse the predefined Mass Functions (10, 11 and 12), which we call it Mass Function of net pay (whole the system) or output of proposed DST-based method (Masoudi, 2013). Mathematically, Dempster Rule of Combination is invented for the case of integrating information of independent sources (Sentz and Ferson, 2002). In this work, fusing data sources are porosity, shale percentage and water saturation. In engineering applications, sometimes users do not take account this limitation for using the rule due to precise and accurate outputs. In another word, this constraint is not a rigid one for engineering applications. Here, in both reservoirs, water saturation does not show any correlation with other two variables; i.e. correlation coefficient is close to zero in all wells. In carbonate reservoir of Mishrif, there is a low rate of correlation. But in sandy Burgan reservoir, correlation coefficient is at maximum: around 0.6, which could be categorized as semi-dependent. Hence, in this study, it is logical to use Dempster Rule of Combination, mathematically.

Resulted Mass Function gives a value from zero to much lower than one for each horizon. Summation of all Mass Function values in each well is equal to one due to definition of Mass Function. 
Finally, summation of Mass Function over a fixed interval, gives a new function, called Belief function, which shows degree of certainty of that interval to be productive. By investigating effect of neighboring horizons on production, when producing from a perforated interval (vertical permeability and viscosity are required), Plausibility Function could be easily calculated by widening the interval of summation with respect to vertical permeability and viscosity values.

\section{Evaluation Criterion}

In order to evaluate the proposed methodology, the output is compared with conventional cutoff-based method. Then, closeness of outputs of both methods is compared with well-test results. From well-test data, oil rate is normalized (divided) by interval length of testing interval, which gives barrel oil

production per day per meter $\left(\frac{b b l o i l}{d a y . m}\right)$, and is plotted against output of both methodologies. In another words, oil rate is normalized by length of testing to remove the effect of testing length on oil rate.

\section{Results and Discussion}

Based on explained procedure in Figure 1, cut-offs of porosity, shale volume and water saturation are determined in each well of two available datasets. For carbonate reservoir of Mishrif, the range of porosity cut-off was from $10 \%$ to $20 \%$. Please consider that, relatively whole the Mishrif is ahigh-quality reservoir (low-shale and high-porosity), and cut-offs of porosity and shale volume are only defined to distinguish the cleanest pay zones from whole the interval to have a pay-categorization through wells. Cut-off of shale volume was below $10 \%$; and cut-off of water saturation was from $50 \%$ to $80 \%$ due to distribution variability of water saturation in each well. 
In the sandy reservoir, defined cut-offs were closer to ordinary values because Burgan reservoir is not as clean as Mishrif. Porosity cut is defined from $4 \%$ to $11 \%$; shale volume between $42 \%$ and $60 \%$; and finally water saturation from $35 \%$ to $61 \%$.

Output of DST-based methodology, conventional method and testing results are plotted in Figure 2 and 3. Figure 2 shows net pay determination results in carbonate Mishrif reservoir of field " $C$ "; whereas productive zone determination in sandy Burgan reservoir of field " $\mathrm{S}$ " is revealed in Figure 3. Scales of outputs of both methodology are converted to $[0,650]$ or $[0,4500]$ to become comparable with well-test values, visually. Following the figure, outputs of these two net pay determination methods are compared under four bullets to check the validity of proposed DST-based methodology.

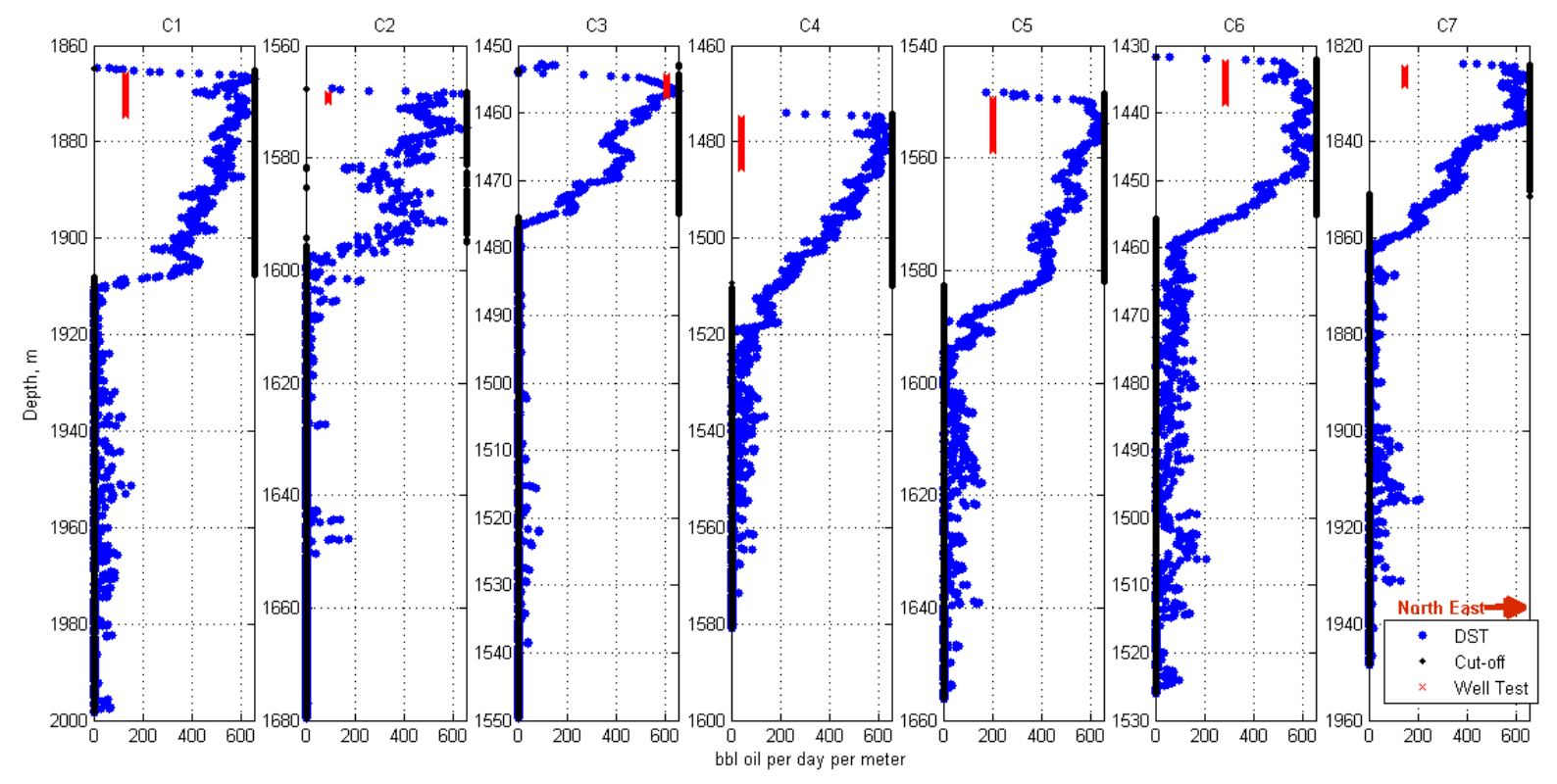

Figure 2 Net pay determination in carbonate Mishrif reservoir in seven wells of field " $C$ ". The vertical axe is depth versus the horizontal axe of production rate per day, per meter $\left(\frac{\text { bbloil }}{\text { day.m }}\right)$. 

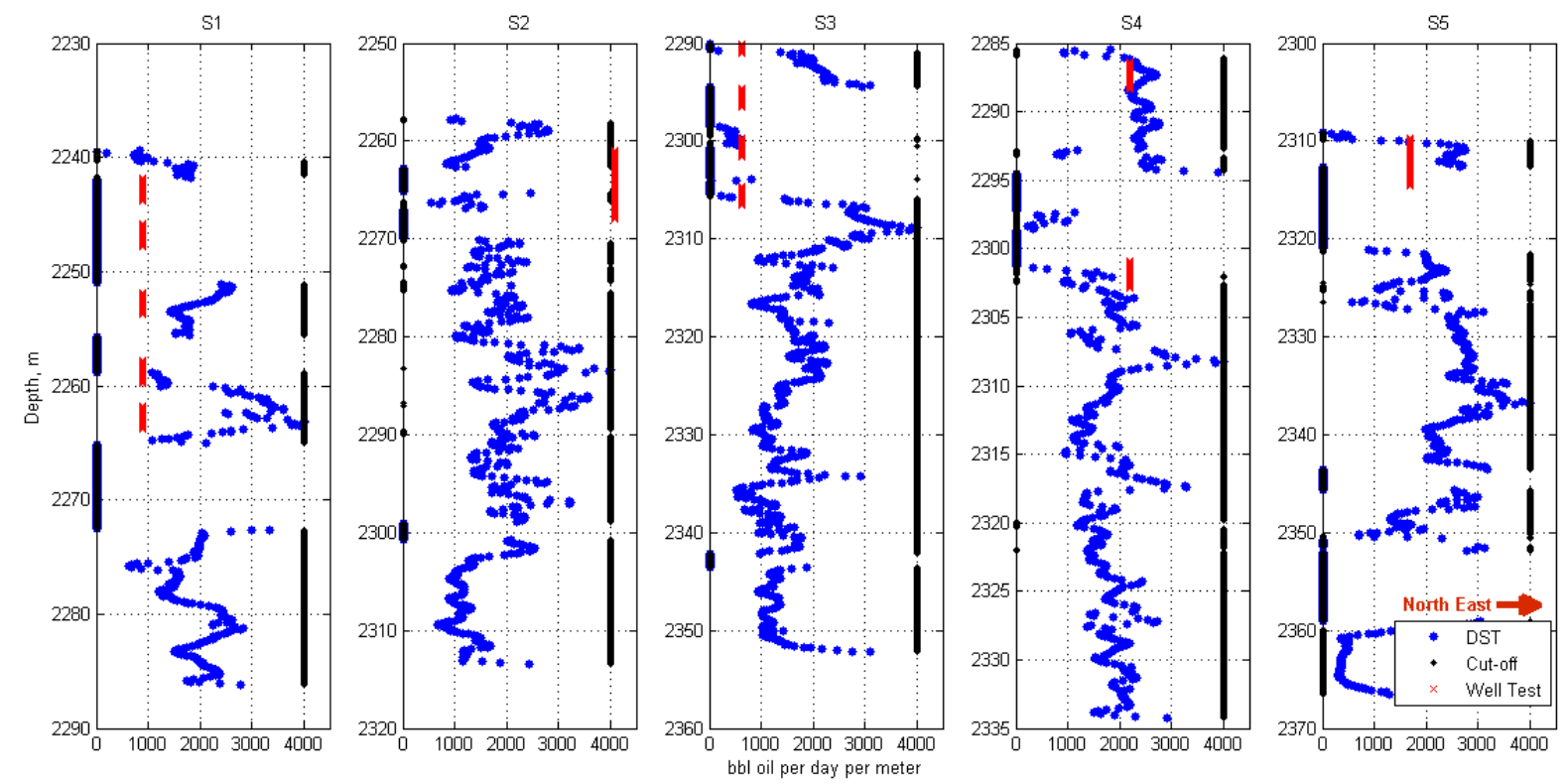

Figure 3 Net pay determination in Sandy Burgan reservoir in five wells of field " $\mathrm{S}$ ". The vertical axe is depth versus the horizontal axe of production rate per day, per meter $\left(\frac{\text { bbloil }}{\text { day.m }}\right)$.

1. Both DST and cut-off-based methodologies are compatible in detecting non-pay zones. In another word, the results would be the same, if someone identifies non-productive zones by each procedure. Please note zero values in Figure 2 and 3.

2. In geology, the borders are mostly transitional, not sharp. Although there is a sharp change in reservoir parameters in the contact of reservoir-cap rocks, changes of reservoir parameters within the reservoir interval is transitional. E.g. water saturation does not convert sharply from say $20 \%$ to $80 \%$, it is gradual. Also the same is for porosity, shale volume and other reservoir parameters. Therefore, dividing the gross into pay and non-pay zones is unrealistic. Cut-off-based method gives a crisp (0-1) output, which is unrealistic within the reservoir rock, while DST-based method gives a more realistic, fuzzified, output.

3. DST output shows a good compatibility with well-test results in Burgan reservoir of "S" field, especially in wells 1, 3, 4 and 5. Therefore, well-test results of " $\mathrm{S}$ " field admit preciseness of DST output. 
In " $\mathrm{C}$ " field, variation of testing results is not shown by DST output due to low variability of oil-rate

values $[0,650] \frac{\text { bbl oil }}{\text { day.m }}$ in this field, comparing to " $\mathrm{S}$ " field, which is $[0,4500]$. As discussed before, cut-off method does not provide any relative pattern of productivity through pay zones.

4. DST method is free of cut-off determination, which is the heart of cut-off-based method of pay zone study. Cut-off determination is a challenging procedure, usually done by analogizing with nearby known oil fields or due to economic considerations. Therefore, proposed method gives a pure technical output, related to geological facts. From another viewpoint, generalizing DST method to adjacent fields or wells does not need another cut-off determination; so, easier generalization ability. In another word, no training is needed for the proposed method. Also there is a less need to optimization.

\section{Conclusion}

A novel procedure of net pay determination, based on Dempster-Shafer Theory (DST), is developed in this work. DST is a powerful decision-making tool in uncertain situations, like here in reservoir condition. Due to results, it is shown that DST-based method of net pay detection is capable in identifying productive zones through oil wells, which the output is compatible with output of conventional method and well-test data. The proposed methodology is admitted by cut-off method of pay determination in two reservoir types: carbonate (Mishrif) and clastic sandy reservoir (Burgan). In addition, by the means of the developed procedure, not only distinguished pay zones are detected fuzzily, which is very similar to real reservoir condition; but also the outputs are more compatible with well-testing results, comparing to conventional cut-off methodology. In addition, there is no need to train the proposed method. Even not an essential optimization is needed. 


\section{Acknowledgment}

The authors would like to acknowledge Iranian Offshore Oil Company for permitting in publishing scientific achievements of the investigation. Also, thank to respected editor, Dr. Tahar Aifa, and anonymous reviewers in spending time to review, and sharing their constructive ideas.

\section{References}

Al-Dabbas, M., Al-Jassim, J. and Al-Jumaily, S., 2010. Depositional environments and porosity distribution in regressive limestone reservoirs of the mishrif formation, Southern Iraq. Arabian Journal of Geosciences, 3(1): 67-78.

Bashari, A., 2007. Integrated 3D seismic and petrophysical data of the Sarvak formation in the Persian Gulf. First Break, 25(11): 45-53.

Chaudhry, A.U., 2004. Introduction, Oil Well Testing Handbook. Gulf Professional Publishing, Burlington, pp. 1-12.

Connell, D.L., Coates, J.A. and Frost, D.A., 1986. Development of a Fluorimetric Method for Detection of Pay Zones During Drilling With Invert Muds. SPE Formation Evaluation, 1(6): 595-602.

Cooke-Yarborqugh, P., 1984. Reservoir Analysis By Wireline Formation Tester: Pressures, Permeabilities, Gradients And Net Pay. The Log Analyst, 15(6): 36-46.

Deakin, M. and Manan, W., 1998. The Integration of Petrophysical Data for the Evaluation of Low Contrast Pay, SPE Asia Pacific Conference on Integrated Modelling for Asset Management. 1998 Copyright 1998, Society of Petroleum Engineers, Inc., Kuala Lumpur, Malaysia, pp. 327-339.

Dempster, A.P., 1967. Upper and lower probabilities induced by a multivalued mapping. The annals of mathematical statistics: 325-339.

Flower, J.G., 1983. Use of Sonic-Shear-Wave/Resistivity Overlay as a Quick-Look Method for Identifying Potential Pay Zones in the Ohio (Devonian) Shale. SPE Journal of Petroleum Technology, 35(3): 638-642.

Honarmand, J. and Moallemi, S.A., 2009. Lithofacies Analysis, Sedimentary Environment and Sequence Stratigraphy of Burgan Formation, North of the Persian Gulf. Stratigraphy and Sedimentology Researches, 25(2): 135-150.

Jensen, J.L. and Menke, J.Y., 2006. Some Statistical Issues in Selecting Porosity Cutoffs for Estimating Net Pay. PetroPhysics, 47(4): 315-320.

Liu, L. and Yager, R., 2008. Classic Works of the Dempster-Shafer Theory of Belief Functions: An Introduction. In: R. Yager and L. Liu (Editors), Classic Works of the Dempster-Shafer Theory of Belief Functions. Studies in Fuzziness and Soft Computing. Springer Berlin Heidelberg, pp. 1-34.

Mahbaz, S., Sardar, H., Namjouyan, M. and Mirzaahmadian, Y., 2011. Optimization of reservoir cut-off parameters: a case study in SW Iran. Petroleum Geoscience, 17(4): 355-363. 
Masoudi, P., 2013. Identifying Net Pay Zones in Oil Wells by Artificial Neural Network and DempsterShafer Theories. In: I.P.G.O. Patent Division, State Organization for Registration of Deeds and Properties (Editor), Iran.

Masoudi, P., Tokhmechi, B., Ansari Jafari, M., Zamanzadeh, S.M. and Sherkati, S., 2012a. Application of Bayesian in determining productive zones by well log data in oil wells. Journal of Petroleum Science and Engineering, 94-95(0): 47-54.

Masoudi, P., Tokhmechi, B., Bashari, A. and Jafari, M.A., 2012b. Identifying productive zones of the Sarvak formation by integrating outputs of different classification methods. Journal of Geophysics and Engineering, 9(3): 282-290.

Masoudi, P., Tokhmechi, B., Jafari, M.A. and Moshiri, B., 2012c. Application of Fuzzy Classifier Fusion in Determining Productive Zones in Oil Wells. Energy Exploration and Exploitation, 30(3): 403-415.

Masoudi, P., Tokhmechi, B., Zahedi, A. and Jafari, M.A., 2011. Developing a Method for Identification of Net Zones Using Log Data and Diffusivity Equation. Journal of Mining and Environment, 2(1): 5360.

Matthews, C.S. and Russell, D.G., 1967. Pressure Buildup and Flow Tests in Wells. : Society of Petroleum Engineers of AIME: 163.

Millikan, C.V., 1925. Use of Gas Meters for Determination of Pay Strata in Oil Sands. 183-195.

Negoita, C., Zadeh, L. and Zimmermann, H., 1978. Fuzzy sets as a basis for a theory of possibility. Fuzzy Sets and Systems, 1: 3-28.

Nottale, L., 1996. Scale relativity and fractal space-time: applications to quantum physics, cosmology and chaotic systems. Chaos, Solitons \& Fractals, 7(6): 877-938.

Rakowsky, U.K., 2007. Fundamentals of the Dempster-Shafer theory and its applications to system safety and reliability modelling. Reliability: Theory \& Applications, 7(3-4): 173-185.

Sentz, K. and Ferson, S., 2002. Combination of Evidence in Dempster-Shafer Theory, New Mexico.

Shafer, G., 1990. Perspectives on the theory and practice of belief functions. International Journal of Approximate Reasoning, 4(5-6): 323-362.

Snyder, R.H., 1971. A Review of the Concepts and Methodology of Determining "Net Pay", Fall Meeting of the Society of Petroleum Engineers of AIME. Society of Petroleum Engineers, New Orleans, Louisiana, pp. 1-12.

Worthington, P.F., 2000. Recognition and evaluation of low-resistivity pay. Petroleum Geoscience, 6(1): 77-92.

Worthington, P.F., 2008. The Application of Cutoffs in Integrated Reservoir Studies. SPE Reservoir Evaluation \& Engineering, 11(6): pp. 968-975.

Worthington, P.F., 2010. Net Pay-What Is It? What Does It Do? How Do We Quantify It? How Do We Use It? SPE Reservoir Evaluation \& Engineering, 13(5): pp. 812-822.

Worthington, P.F. and Cosentino, L., 2005. The Role of Cut-offs in Integrated Reservoir Studies. SPE Reservoir Evaluation \& Engineering, 8(4): pp. 276-290. 